\title{
Determinants of $\mathrm{Fi}, \mathrm{O}_{2}$ with oxygen supplementation during noninvasive two-level positive pressure ventilation
}

\author{
F. Thys*, G. Liistro*, O. Dozin*, E. Marion*, D.O. Rodenstein ${ }^{\#}$
}

\begin{abstract}
Determinants of $\mathrm{F}_{i} \mathrm{O}_{2}$ with oxygen supplementation during noninvasive two-level positive pressure ventilation. F. Thys, G. Liistro, O. Dozin, E. Marion, D.O. Rodenstein. (C) ERS Journals Ltd 2002.

ABSTRACT: To maintain arterial oxygen saturation $\left(\mathrm{S}_{\mathrm{a}}, \mathrm{O}_{2}\right)$ above $90 \%$ in patients with acute respiratory failure, oxygen $\left(\mathrm{O}_{2}\right)$ is often added to the circuit of two-level noninvasive positive pressure ventilation (NPPV). However, the final inspiratory oxygen fraction $\left(\mathrm{Fi}_{1}, \mathrm{O}_{2}\right)$ is not known.

To clarify this issue, the effect of different inspiratory positive airway pressures (IPAP) of the oxygen tubing connection site and the flow rate of $\mathrm{O}_{2}$, on $\mathrm{Fi}_{1}, \mathrm{O}_{2}$ was assessed. The effects of the tidal volume $\left(V_{\mathrm{T}}\right)$ and the respiratory rate on the $\mathrm{Fi}, \mathrm{O}_{2}$ were then clarified in a model study.

The $\mathrm{Fi}_{\mathrm{i}} \mathrm{O}_{2}$ varied depending on the point where $\mathrm{O}_{2}$ was added to the circuit. When all other variables were constant, the connection closest to the exhaust port (ventilator side) gave the highest $\mathrm{Fi}, \mathrm{O}_{2}$. Increases in IPAP led to decreases in $\mathrm{Fi}, \mathrm{O}_{2}$. Finally, $\mathrm{Fi}, \mathrm{O}_{2}$ increased with $\mathrm{O}_{2}$ flow, although it was difficult to obtain an $\mathrm{Fi}_{1}, \mathrm{O}_{2}>0.30$ unless very high $\mathrm{O}_{2}$ flows were used. Paradoxically, NPPV with low IPAP values and without $\mathrm{O}_{2}$ supplementation led to a $\mathrm{Fi}_{\mathrm{i}} \mathrm{O}_{2}<0.21$ at the circuit-patient interface. $V \mathrm{~T}$ and respiratory rate did not appear to influence $\mathrm{Fi}_{1}, \mathrm{O}_{2}$.

To conclude, when using noninvasive positive pressure ventilation with two-level respirators, oxygen should be added close to the exhaust port (ventilator side) of the circuit. If inspiratory airway pressure levels are $>12 \mathrm{cmH}_{2} \mathrm{O}$, oxygen flows should be at least $4 \mathrm{~L} \cdot \mathrm{min}^{-1}$. Eur Respir J 2002; 19: 653-657.
\end{abstract}

*Emergency Dept and ${ }^{\#}$ Pneumology Dept, Cliniques Universitaires SaintLuc, Université Catholique de Louvain, Brussels, Belgium.

\author{
Correspondence: F. Thys \\ Service des Urgences \\ Cliniques Universitaires Saint-Luc \\ Université Catholique de Louvain \\ Avenue Hippocrate 10 \\ B-1200 Bruxelles \\ Belgium \\ Fax: 3227641620 \\ E-mail: Thys@rean.ucl.ac.be
}

Keywords: Inspiratory oxygen fraction noninvasive positive pressure ventilation

oxygen

Received: July 242001

Accepted after revision September 10 2001

Currently, two-level noninvasive positive pressure ventilation (NPPV) is used in the treatment of patients with acute respiratory failure in intensive care units [1-7], general pulmonary wards [8, 9] and emergency depts [10-12]. In these settings, supplemental oxygen $\left(\mathrm{O}_{2}\right)$ is often added to the circuit of the ventilators to maintain an adequate arterial $\mathrm{O}_{2}$ saturation $\left(\mathrm{Sa}_{\mathrm{a}} \mathrm{O}_{2}\right)$. The inspired oxygen fraction $\left(\mathrm{Fi}, \mathrm{O}_{2}\right)$ is generally unknown, and could be influenced by a number of factors such as the inspiratory positive airway pressure (IPAP), the expiratory positive airway pressure (EPAP), the $\mathrm{O}_{2}$ flow rate and the site where $\mathrm{O}_{2}$ is added to the circuit etc.

At the present time, there is no published data on the best way to add $\mathrm{O}_{2}$ to the circuit of a two-level NPPV (i.e. what level of flow is required, where should the connection be made). To clarify this matter, a two-part study was conducted. First, in a clinical setting, the effect of different IPAP values of the $\mathrm{O}_{2}$ tubing connection site and the flow rate of $\mathrm{O}_{2}$, on the $\mathrm{Fi}_{1} \mathrm{O}_{2}$ was investigated. Second, an experimental study to clarify the effect of the tidal volume $(V \mathrm{~T})$ and the respiratory rate on the $\mathrm{Fi}_{1}, \mathrm{O}_{2}$ was conducted.

\section{Materials and methods}

\section{Clinical study}

Three normal volunteers, aged 21, 24 and $27 \mathrm{yrs,}$ in good health and having never smoked were investigated. Two-level NPPV was initiated with a barometric ventilator (Bilevel positive airway pressure device (BiPAP $\AA$ S/T-D30; Respironics Inc., Murrysville, PA, USA), through a face mask (Bird Corporation, CA, USA), with the subject in a semirecumbent position. The tubing connecting the ventilator to the mask had a volume of $565 \mathrm{~mL}$ and a length of $191 \mathrm{~cm}$. The volume between the mask and the exhaust port as depicted in figure 1 was $19.4 \mathrm{~mL}$. Initially, the EPAP was set at $2 \mathrm{cmH}_{2} \mathrm{O}$ (the minimal pressure level of the machine) and the IPAP was set at $2 \mathrm{cmH}_{2} \mathrm{O}$. The IPAP was then increased to 8 , 12, 16 and $20 \mathrm{cmH}_{2} \mathrm{O}$. The machine was used in the assist-control mode with a backup frequency of 12 breaths $\cdot \mathrm{min}^{-1}$ and a back-up inspiratory/expiratory time ratio of $50 \%$. The device was used with a whisper swivel-type of exhaust port. Different levels of $\mathrm{O}_{2}$ flow at several different locations in the patient circuit were added. The $\mathrm{O}_{2}$ was added at the exit of the BiPAP unit (proximal injection), before the exhaust port (middle injection) and finally at the patient connection immediately before the mask (distal injection) as shown in figure 1 . For each level of pressure and connection point, $0,2,4,6,8,10,12,14$ and $16 \mathrm{~L} \cdot \mathrm{min}^{-1}$ of $\mathrm{O}_{2}$ were added. The additional $\mathrm{O}_{2}$ came from a high-pressure source governed by a flow-meter assembly (Thorpe-tube flow meter) and the connection was made with a $\mathrm{T}$-connector.

For each value of IPAP, $\mathrm{O}_{2}$ flow rate and 

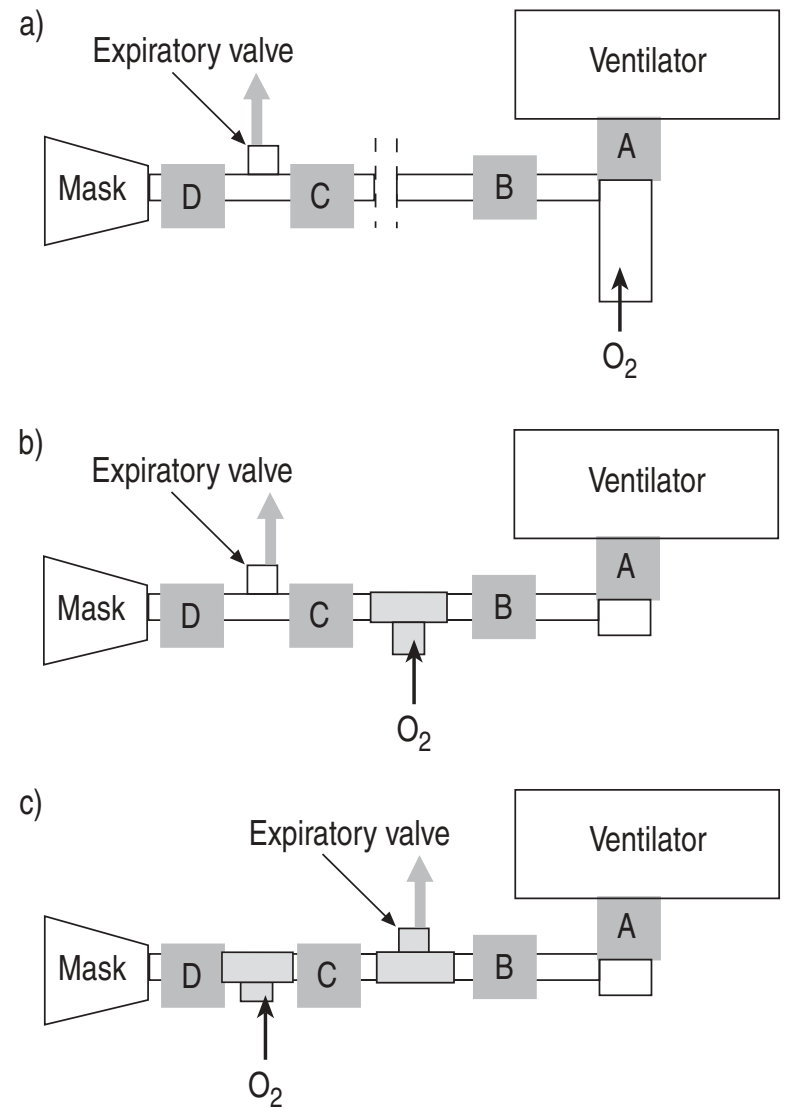

Fig. 1.-Schematic representation of the three types of circuit. a) proximal injection; b) middle injection; c) distal injection. $\mathrm{O}_{2}$ : oxygen. A: location A, at the exit of the Bilevel positive airway pressure device; B: B, before the first connector; $\mathrm{C}$ : $\mathrm{C}$, between the two T-connectors; D: D, at the terminal part of the circuit before the mask.

connection point, the $F \mathrm{I}, \mathrm{O}_{2}$ was measured with an $\mathrm{O}_{2}$ monitor (Oxygen monitor 5120; Ohmeda, Madison, WI, USA). Calibration was carried out according to the manufacturers' recommended procedure. The response time of the $\mathrm{O}_{2}$ monitor was measured at several different conditions of IPAP and respiratory rate. The time taken for a $90 \%$ change was $43 \mathrm{~s}$ and the time taken for a two-third change was $21 \mathrm{~s}$. All measurements were performed at a steady state. The $F \mathrm{i}, \mathrm{O}_{2}$ was measured at 4 points along the circuit using a second T-connector for each circuit, as shown in figure 1: location $\mathrm{A}$ : at the exit of the BiPAP unit; location B: before the first T-connector (exhaust port or $\mathrm{O}_{2}$ addition); location $\mathrm{C}$ : between the two T-connectors; location D: at the terminal part of the circuit just before the mask. The BiPAP system was cycled at each test setting until the reading on the $\mathrm{O}_{2}$ analyser stabilized. The final value was the result of three successive measures.

\section{Model study}

The effects of $V \mathrm{~T}$ and the respiratory rate were investigated with a test lung. The test lung was a bicompartmental model of balloons in a Plexiglas box.
Between the lung model and the ventilator, a low and a high linear resistance were added to modify the $V$ T. A number 3 Fleisch pneumotachograph (Fleisch, Lausanne, Switzerland) with a Validyne pressure transducer (range $\pm 5 \mathrm{cmH}_{2} \mathrm{O}$ ) (Validyne Engineering Corporation, Northridge, CA, USA) was used for airflow measurement and integration, yielding $V \mathrm{~T}$. $F_{1}, \mathrm{O}_{2}$, airflow and $V \mathrm{~T}$, with the two resistances and two different rates of ventilation were recorded. The barometric ventilator used in the clinical study was also used in this set of experiments.

Initially, the EPAP was set at $2 \mathrm{cmH}_{2} \mathrm{O}$ and the IPAP was set at $2 \mathrm{cmH}_{2} \mathrm{O}$. The IPAP was then increased to 8, 12, 16 and $20 \mathrm{cmH}_{2} \mathrm{O}$. The barometric ventilator was used in the controlled mode with two different frequencies, 14 and 22 breaths $\cdot \mathrm{min}^{-1}$. The inspiratory/expiratory ratio was $50 \%$. The $\mathrm{O}_{2}$ was added before the exhaust port (middle injection in fig. 1). For each level of pressure, $0,2,4,6,8,10,12$, 14 and $16 \mathrm{~L} \cdot \mathrm{min}^{-1}$ of $\mathrm{O}_{2}$ were added. The additional $\mathrm{O}_{2}$ came from a high-pressure source governed by a flow-meter assembly and the connection was made with a T-connector. For each value IPAP, $\mathrm{O}_{2}$ flow rate and value of resistance, the $\mathrm{Fi}_{\mathrm{i}} \mathrm{O}_{2}$ was measured just before the connection to the lung model with an $\mathrm{O}_{2}$ monitor. The BiPAP System was cycled at each test setting until the reading on the $\mathrm{O}_{2}$ analyser stabilized. The final value was the result of three successive measures.

\section{Statistical analysis}

In the clinical part of this study, the relationships between $\mathrm{Fi}_{1} \mathrm{O}_{2}$ and each of the following determinants: $\mathrm{O}_{2}$ connection point, IPAP, location of measurement and $\mathrm{O}_{2}$ flow were tested. A standard linear regression analysis was used. The different relationships obtained were compared using covariance analysis, in order to test the difference between their slopes and intercepts. The same linear regression and covariance analysis were applied to the variables recorded during the experimental part of the investigation.

\section{Results}

\section{Clinical study}

Influence of the oxygen connection point. Figure 2 shows the $\mathrm{Fi}_{1} \mathrm{O}_{2}$ values for an IPAP of $8 \mathrm{cmH}_{2} \mathrm{O}$ and an EPAP of $2 \mathrm{cmH}_{2} \mathrm{O}$, according to the three connection points (proximal, middle, distal injection). It was shown that, the $\mathrm{Fi}_{1}, \mathrm{O}_{2}$ changed according to which connection point was utilized $(\mathrm{p}<0.05)$. For a given $\mathrm{O}_{2}$ flow, the $F \mathrm{i}, \mathrm{O}_{2}$ was greatest when the $\mathrm{O}_{2}$ was connected just before the exhaust port. This applied to all levels of IPAP and $\mathrm{O}_{2}$ flow and to all measurement locations.

Influence of the inspiratory positive airway pressure. Figure 3 shows the $\mathrm{Fi}_{1} \mathrm{O}_{2}$ values measured in location $\mathrm{C}$ with the $\mathrm{O}_{2}$ connected at the middle injection point, according to each level of IPAP. In this case, 


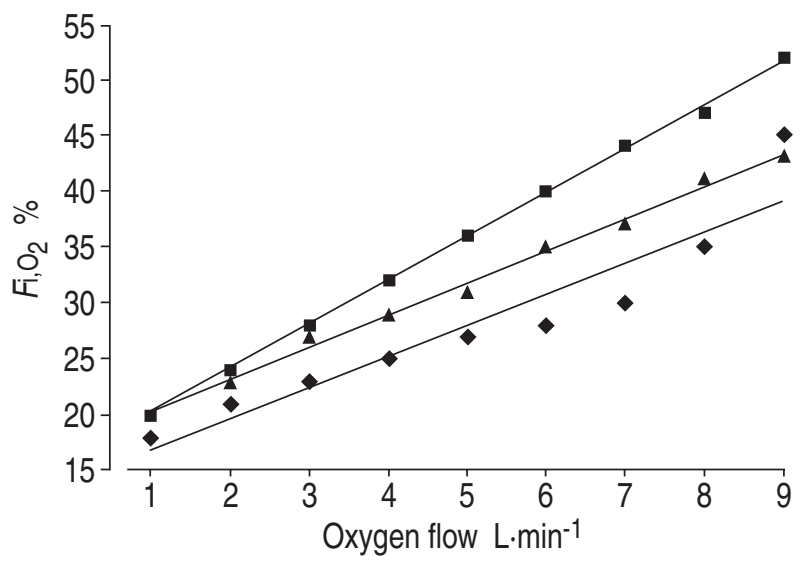

Fig. 2. - Trends for the inspiratory oxygen fraction $\left(\mathrm{Fi}_{2} \mathrm{O}_{2}\right)$ values for an inspiratory positive airway pressure of $8 \mathrm{cmH}_{2} \mathrm{O}$ at location C. $\bullet$ : proximal injection; $\boldsymbol{\square}$ : middle injection; $\boldsymbol{\Delta}$ : distal injection.

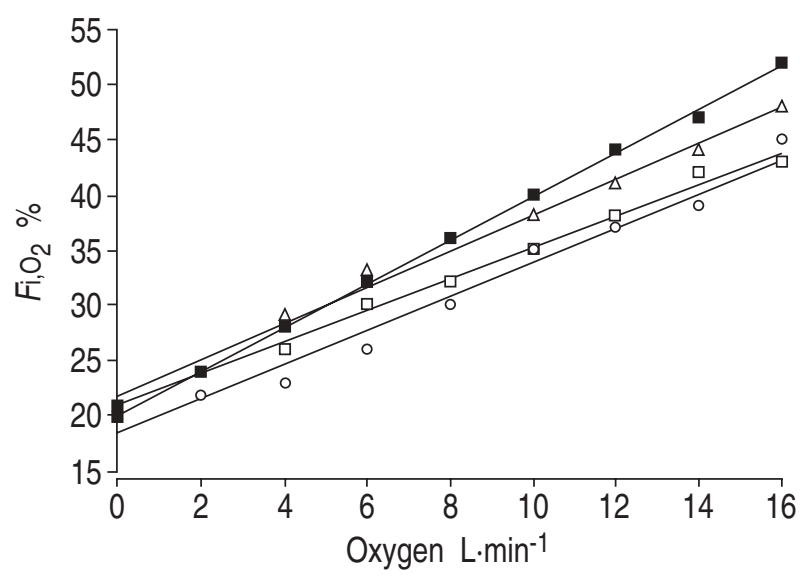

Fig. 3.-Inspiratory oxygen fraction $\left(\mathrm{Fi}_{\mathrm{i}} \mathrm{O}_{2}\right)$ values at location $\mathrm{C}$ with the oxygen connection at the middle injection for each level of inspiratory positive airway pressure (IPAP). $\mathbf{\square}$ : IPAP $8 ; \triangle$ : IPAP 12; $\square$ : IPAP 16; ○: IPAP 20.

when levels of $\mathrm{O}_{2}$ flow were low, the value of $\mathrm{Fi}_{1}, \mathrm{O}_{2}$ increased as IPAP increased from 8 to $12 \mathrm{cmH}_{2} \mathrm{O}$ $(\mathrm{p}<0.05)$, but there was a decrease in $\mathrm{Fi}_{\mathrm{i}, \mathrm{O}_{2}}$ when pressure was increased from 12 to 16 and $20 \mathrm{cmH}_{2} \mathrm{O}$ $(\mathrm{p}<0.05)$. At higher levels of $\mathrm{O}_{2}$ flow, $\mathrm{Fi}_{1} \mathrm{O}_{2}$ decreased when the IPAP was increased from 8 to 12,16 and $20 \mathrm{cmH}_{2} \mathrm{O}$. There was no significant difference between IPAP of 16 and $20 \mathrm{cmH}_{2} \mathrm{O}$. Therefore in this circuit, the highest $F \mathrm{Fi}_{2} \mathrm{O}_{2}$ was obtained with an IPAP of $8 \mathrm{cmH}_{2} \mathrm{O}$. These results did not apply to all circuits, connection points or $\mathrm{O}_{2}$ flows. For instance, at the proximal injection point, when measured at location $\mathrm{C}$, the $\mathrm{Fi}_{\mathrm{i}} \mathrm{O}_{2}$ was significantly lower for an IPAP of $20 \mathrm{cmH}_{2} \mathrm{O}$ but there was no difference between the other pressure levels.

Influence of the location of measurement. Figure 4 shows the $\mathrm{Fi}_{1} \mathrm{O}_{2}$ values for an IPAP of $16 \mathrm{cmH}_{2} \mathrm{O}$ measured in the four locations, with $\mathrm{O}_{2}$ connected at the middle injection point. The $\mathrm{Fi}_{1} \mathrm{O}_{2}$ increased as the measurement point was moved closer to the patient

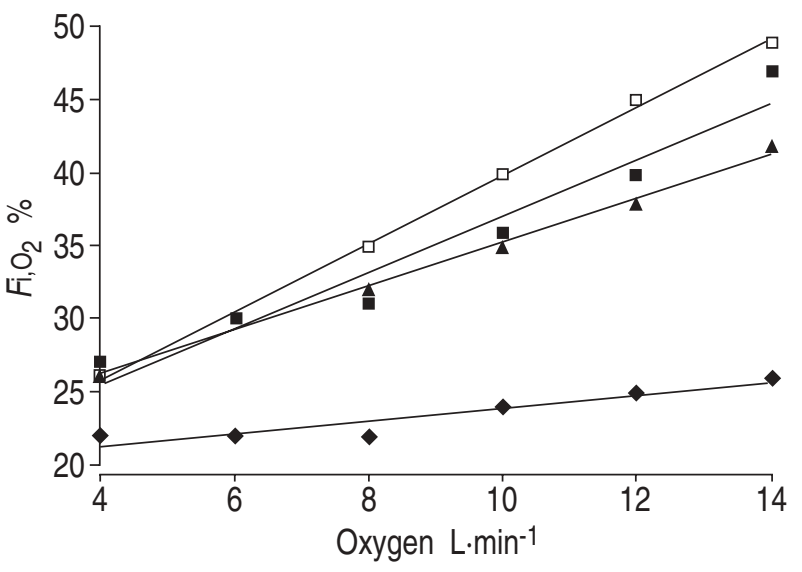

Fig. 4.- Inspiratory oxygen fraction $\left(\mathrm{Fi}_{\left.\mathrm{i}, \mathrm{O}_{2}\right)}\right.$ values for an inspiratory positive airway pressure (IPAP) of $16 \mathrm{cmH}_{2} \mathrm{O}$ with the oxygen connection at the middle injection for each four measurement locations. $\diamond$ : $\mathbf{\square}: \mathrm{B} ; \boldsymbol{\Delta}: \mathrm{C} ; \square$ : D. Table 1: Influence of IPAP on the $F \mathrm{I}_{,} \mathrm{O}_{2}$ value in the location $\mathrm{C}$.

$(\mathrm{p}<0.01)$. This was true for all IPAP, $\mathrm{O}_{2}$ flows and connection points.

Influence of oxygen flow. When measured at location $\mathrm{D}$, with no added $\mathrm{O}_{2}$ and an IPAP $<16 \mathrm{cmH}_{2} \mathrm{O}$, the $\mathrm{Fi}, \mathrm{O}_{2}$ decreased along the circuit and fell below $21 \%$. With an $\mathrm{O}_{2}$ flow of $2 \mathrm{~L} \cdot \mathrm{min}^{-1}$, the $F_{1}, \mathrm{O}_{2}$ decreased with increasing IPAP levels with measurements performed at location $\mathrm{D}$, but not at the other locations. This applied to all three connection points. For high IPAP levels (16 and $20 \mathrm{cmH}_{2} \mathrm{O}$ ), it was difficult to obtain an $\mathrm{Fi}_{1}, \mathrm{O}_{2}>0.35$ unless very high $\mathrm{O}_{2}$ flows were used (table 1).

\section{Model study}

For each level of IPAP, $V \mathrm{~T}$ was lower with a higher resistance (tables 2 and 3). For a given IPAP and resistance, $V \mathrm{~T}$ decreased with an increase in frequency. Under both conditions, it was observed that there was no effect of $V \mathrm{~T}$ or respiratory frequency on the $\mathrm{Fi}_{\mathrm{i}} \mathrm{O}_{2}$

Table 1. - Influence of inspiratory positive airway pressure (IPAP) on the inspiratory oxygen fraction value in the location C: middle injection

\begin{tabular}{lccccc}
\hline $\mathrm{O}_{2}$ flow L·min & \multicolumn{5}{c}{ IPAP } \\
\cline { 2 - 6 } & 2 & 8 & 12 & 16 & 20 \\
\hline 0 & 19 & 20 & 21 & 21 & 21 \\
2 & 26 & 24 & 24 & 24 & 22 \\
4 & 31 & 28 & 29 & 26 & 23 \\
6 & 38 & 32 & 33 & 30 & 26 \\
8 & 45 & 36 & 36 & 32 & 30 \\
10 & 53 & 40 & 38 & 35 & 35 \\
12 & 63 & 44 & 41 & 38 & 37 \\
14 & 65 & 47 & 44 & 42 & 39 \\
16 & 67 & 52 & 48 & 43 & 45 \\
\hline
\end{tabular}

Data are presented as $\% . \mathrm{O}_{2}$ : oxygen. 
Table 2. - Results from the model study at low resistance with 14 breaths $\cdot \mathrm{min}^{-1}$

$\mathrm{O}_{2}$ flow $\mathrm{L} \cdot \mathrm{min}^{-1} \quad \mathrm{Fi}_{1} \mathrm{O}_{2}$

IPAP 8 IPAP $12 \quad$ IPAP $16 \quad$ IPAP 20

\begin{tabular}{lcccc}
\hline 0 & 20 & 21 & 21 & 21 \\
2 & 23 & 26 & 24 & 25 \\
4 & 29 & 30 & 30 & 30 \\
6 & 37 & 38 & 37 & 35 \\
8 & 46 & 49 & 45 & 42 \\
10 & 67 & 65 & 56 & 48 \\
Tidal volume $\mathrm{mL}$ & 414 & 617 & 797 & 955 \\
\hline
\end{tabular}

$\mathrm{Fi}_{\mathrm{i}} \mathrm{O}_{2}$ : inspiratory oxygen fraction; IPAP: inspiratory positive airway pressure; $\mathrm{O}_{2}$ : oxygen.

Table 3. - Results from the model study at high resistance with 14 breaths $\cdot \min ^{-1}$

$\mathrm{O}_{2}$ flow $\mathrm{L} \cdot \mathrm{min}^{-1} \quad \mathrm{Fi}_{\mathrm{i}, \mathrm{O}_{2}}$

IPAP 8 IPAP $12 \quad$ IPAP $16 \quad$ IPAP 20

\begin{tabular}{lcccc}
\hline 0 & 20 & 21 & 21 & 21 \\
2 & 23 & 25 & 26 & 26 \\
4 & 28 & 31 & 33 & 32 \\
6 & 36 & 38 & 40 & 39 \\
8 & 45 & 46 & 46 & 43 \\
10 & 60 & 56 & 56 & 51 \\
Tidal volume mL & 346 & 526 & 707 & 857 \\
\hline
\end{tabular}

$\mathrm{Fi}_{\mathrm{i}} \mathrm{O}_{2}$ : inspiratory oxygen fraction; IPAP: inspiratory positive airway pressure; $\mathrm{O}_{2}$ : oxygen.

values recorded at different $\mathrm{O}_{2}$ flows, irrespective of IPAP level.

\section{Discussion}

In the clinical setting, $\mathrm{O}_{2}$ is frequently added to the circuit of two-level NPPV, to maintain $\mathrm{Sa}_{\mathrm{a}} \mathrm{O}_{2}$ above $90 \%$, in the treatment of patients with acute respiratory failure. $\mathrm{O}_{2}$ is added to the circuit of the ventilator at unspecified points and at different flow rates and the exact concentration of $\mathrm{O}_{2}$ delivered cannot be measured.

In this investigation, the site of $\mathrm{O}_{2}$ injection appears to be an important factor influencing the concentration of $\mathrm{O}_{2}$ that the patient receives. The highest values of $\mathrm{Fi}, \mathrm{O}_{2}$ were recorded when the $\mathrm{O}_{2}$ was introduced to the circuit just before the expiratory port. Connecting $\mathrm{O}_{2}$ closer to the respirator or closer to the patient resulted in reduced values of $\mathrm{Fi}_{1} \mathrm{O}_{2}$ for the same $\mathrm{O}_{2}$ flows and ventilator settings. The mixture of air and $\mathrm{O}_{2}$ is probably more homogeneous when injected in the middle than in the proximal or distal locations. It may be hypothesized that if the $\mathrm{O}_{2}$ flow is added between the mask and the expiratory port, the blending of the expiratory and inspiratory gases could lower the $\mathrm{Fi}_{\mathrm{i}} \mathrm{O}_{2}$ on the patient's side. $\mathrm{O}_{2}$ was delivered continuously and although it was not studied, there is a possibility that if $\mathrm{O}_{2}$ was supplied just before the whisper valve it may form a reservoir for the next inspiration. If it was supplied closer to the mask, the $\mathrm{O}_{2}$ delivered during expiration might be exhaled through the whisper valve and lost to the patient.

The level of IPAP also had an influence on the $\mathrm{Sa}_{\mathrm{a}} \mathrm{O}_{2}$. The highest $\mathrm{Fi}_{1} \mathrm{O}_{2}$ values into the mask were obtained at IPAPs between $8-16 \mathrm{cmH}_{2} \mathrm{O}$. Furthermore, a drop in the $\mathrm{Fi}_{\mathrm{i}} \mathrm{O}_{2}$ value was observed in the distal part of the circuit with IPAP pressures of $<8 \mathrm{cmH}_{2} \mathrm{O}$. An $\mathrm{Fi}_{1}, \mathrm{O}_{2}<21 \%$ without additional $\mathrm{O}_{2}$ and IPAP values $<16 \mathrm{cmH}_{2} \mathrm{O}$ appeared to be indirect signs of rebreathing and dilution. Rebreathing phenomena have been reported previously with IPAP $<8 \mathrm{cmH}_{2} \mathrm{O}$ [13, 14]. At low levels of pressure $\left(<8 \mathrm{cmH}_{2} \mathrm{O}\right)$ and without supplemental $\mathrm{O}_{2}$ the patients may be submitted to a hypoxic gas mixture. It could be argued, that the long response time of the $\mathrm{O}_{2}$ monitor produces recordings resulting from the mixing of inspiratory and expiratory gases. Thus, the $\mathrm{Fi}_{1} \mathrm{O}_{2}$ would be artefactually lowered by the fractional expired $\mathrm{O}_{2}$. However, this study also reports results from the $\mathrm{O}_{2}$ monitor when located at position $\mathrm{B}$, where the influence of expired gas would be minimal. Once $\mathrm{O}_{2}$ was added into the circuit, the $\mathrm{Fi}_{\mathrm{i}} \mathrm{O}_{2}$ decreased with increasing IPAP. This seems logical, as higher pressures lead to higher flows of air for a fixed flow of $\mathrm{O}_{2}$, probably an unfavourable situation for this mixing.

It is reassuring that in this experimental model, respiratory rate and $V \mathrm{~T}$ do not affect the $F_{\mathrm{i}, \mathrm{O}_{2}}$. Although for completion of data collection, the $\mathrm{Fi}_{\mathrm{i}} \mathrm{O}_{2}$ at different locations was measured, it was clear that only location D was of clinical relevance, as it was the location best representing the central inspired $\mathrm{O}_{2}$ concentration at the patient-circuit interface. Measurements performed within the mask (not used in this study) may give a better idea of the real inspired $F_{1}, \mathrm{O}_{2}$ but the precision and accuracy of the $\mathrm{O}_{2}$-sensor cell could be unfavourably influenced within the mask. Results may also be different with a nasal mask but the direction of the change would probably be the same.

Conventional ventilators provided with conventional expiratory valves and single tubing still allow some mixing of inspired and expired gases between the airway outlet and the expiratory valve location. These results could therefore be extended to the conventional ventilator, although the effect would probably be reduced. By contrast, ventilators provided with separate expiratory and inspiratory tube lines should not have this problem, although this remains to be tested.

A caveat concerning the absence of the influence of $V \mathrm{~T}$ on $\mathrm{Fi}_{\mathrm{i}} \mathrm{O}_{2}$ seems necessary. Indeed the potential role of $V \mathrm{~T}$ on a model lung, where there was neither $\mathrm{O}_{2}$ consumption nor carbon dioxide production, was assessed. One might suppose that $V_{\mathrm{T}}$ could behave in a more disturbing way in a patient, by its influence on dead space and, eventually, rebreathing into the distal part of the circuit. Nevertheless, the model data in this study ( $V$ T changing two-fold) suggests that, the problem should be slight.

To the best of the authors' knowledge, this is the first study examining the determinants of $\mathrm{Fi}_{\mathrm{i}} \mathrm{O}_{2}$ during 
NPPV. This is an incomplete study. Indeed measurements using one model of two-level NPPV, only one connecting tube and a single face mask have been performed. The subjects studied were normal subjects, with normal lung mechanics and normal dead spaces. Moreover, the possible effect of change in EPAP on $\mathrm{Fi}_{\mathrm{i}} \mathrm{O}_{2}$ has not been investigated. It is clear that these results could be different if measurements were performed with different respirators, different tubing lengths and volumes, and in patients with different lung diseases. Nevertheless, the important point still remains that $\mathrm{Fi}, \mathrm{O}_{2}$ depends on several determinants in addition to $\mathrm{O}_{2}$ flow.

To conclude, when using supplemental oxygen during noninvasive positive pressure ventilation, the inspiratory oxygen fraction depended on three major factors: the point where oxygen is added into the circuit, the level of inspiratory positive airway pressure, and the oxygen flow rate. The respiratory rate and the tidal volume did not influence the delivered inspiratory oxygen fration. For inspiratory positive airway pressures $>12 \mathrm{cmH}_{2} \mathrm{O}$, the inspiratory oxygen fraction flows should be at least $4 \mathrm{~L} \cdot \mathrm{min}^{-1}$. An inspiratory oxygen fraction $\geqslant 0.5$ requires a very high level of oxygen flow. This was a limited experimental study, and should be considered as a guide rather than a complete predictor for different two-level pressure support ventilators used with various masks or different levels of expiratory positive airway pressures.

Acknowledgements. The authors would like to thank O. Pitance and D. Reychler for their help in collecting the data and N. Stroobant for her constant dedication to this study.

\section{References}

1. Meyer TJ, Hill NS. Non invasive positive pressure ventilation to treat respiratory failure. Ann Intern Med 1994; 120: 760-770.

2. Freichels TA. Palliative ventilatory support: Use of non invasive positive pressure ventilation in terminal respiratory insufficiency. Am J Crit Care 1994; 3: 6-10.
3. Pennock BE, Crawshaw L, Kaplan PD. Non invasive nasal mask ventilation for acute respiratory failure: Institution of a new therapeutic technology for routine use. Chest 1994; 105: 441-444.

4. Wysocki M, Tric L, Wolff MA, Gertner J, Millet H, Herman B. Non invasive pressure support ventilation in patients with acute respiratory failure. Chest 1993; 103: 907-913.

5. Foglio C, Vittaca M, Quadri A, Scalvini S, Marangoni $\mathrm{S}$, Ambrosino $\mathrm{N}$. Acute exacerbation in COLD patients: Treatment using positive pressure ventilation by nasal mask. Chest 1992; 101: 1533-1538.

6. Meduri GU. Noninvasive positive pressure ventilation in patients with acute respiratory failure. Clin Chest Med 1996; 17: 513-533.

7. Meduri GU, Abou-Shala N, Fox RC, Jones CB, Leeper KV, Wunderink RG. Noninvasive face mask mechanical ventilation in patients with acute hypercapnic respiratory failure. Chest 1991; 100: 445-454.

8. Barbe F, Togores B, Rubi M, Pons S, Maimo A, Agusti AG. Noninvasive ventilatory support does not facilitate recovery from acute respiratory pulmonary disease. Eur Respir J 1996; 9: 1240-1245.

9. Bott J, Carroll M, Conway J, et al. A randomizedcontrolled study of nasal intermittent positive pressure ventilation in acute exacerbations of chronic obstructive airways disease. Lancet 1993; 341: 1555-1557.

10. Pollack CV, Torres MT, Alexander L. Feasibility study of the use of bilevel positive airway pressure for respiratory support in emergency department. Ann Emerg Med 1996; 27: 189-192.

11. Celikel T, Sungur M, Ceyhan B, Karakurt S. Comparison of noninvasive positive pressure ventilation with standard medical therapy in hypercapnic acute respiratory failure. Chest 1998; 114: 1636-1642.

12. Thys F, Roeseler J, Delaere S, et al. Two-level non invasive positive pressure ventilation in the initial treatment of acute respiratory failure in an emergency department. Eur J Emerg Med 1999; 6: 207-214.

13. Ferguson GT, Gilmartin $\mathrm{M} . \mathrm{CO}_{2}$ rebreathing during BiPAP ventilatory assistance. Am J Respir Crit Care Med 1995; 151: 1126-1135.

14. Lofaso F, Brochard L, Touchard D, Hang T, Harf A, Isabay D. Evaluation of carbon dioxyde rebreathing during pressure support ventilation with airway management system (BiPAP) devices. Chest 1995; 108: $772-78$. 